\title{
Asymmetric Michael reaction catalyzed by mimicked peptides
}

\begin{abstract}
Peptides mimicked from active site of promiscuous aldo-ketoreductase were synthesized and tested as asymmetry catalysts in the Michael adduct reaction of aldehydes or ketones with nitroolefins to furnish the corresponding $\gamma$-nitroaldehydes, $\gamma$-nitroketones with up to 93 $\%$ yield, 99:1 dr and $71 \%$ ee at room temperature and on eco-friendly solvents. Aspartic acid residue as second amino acid produced greater enantioselectivity.
\end{abstract}

Keyword: Michael adduct; Asymmetry; Peptides; Aldo-ketoreductase; Promiscuous 